\title{
Glucagon and Canine Mesenteric Hemodynamics: Effects on Superior Mesenteric Arteriovenous and Nutrient Capillary Blood Flow
}

\author{
Andris Kazmers, M.D., Cameron D. Wright, M.D., \\ Walter M. Whitehouse, Jr., M.D., Gerald B. Zelenock, M.D., \\ S. Martin Lindenauer, M.D., and James C. Stanley, M.D. \\ Division of Peripheral Vascular Surgery, Department of Surgery, University of \\ Michigan Medical School, Ann Arbor, Michigan 48109
}

Presented at the Annual Meeting of the Association for Academic Surgery, Birmingham, Alabama, November 5-8, 1980

\begin{abstract}
The objective of this investigation was to define the splanchnic hemodynamic effects of parenterally administered glucagon in a canine model. Measurements in six dogs at baseline and at 10,20 , and 30 min during constant intravenous infusion of glucagon at $1 \mu \mathrm{g} / \mathrm{kg} / \mathrm{min}$ included: Cardiac output (CO), mean arterial pressure, total peripheral vascular resistance (TPR), superior mesenteric artery flow (SMAQ), portal venous pressure (PVP), superior mesenteric artery vascular resistance (SMAR), percentage SMA flow through arteriovenous anastomoses (AVA\%) determined by ${ }^{99 m} \mathrm{Tc}$ microsphere technique, as well as volume flow through AVA (AVAQ), and volume flow through the SMA nutrient capillary circulation (NCQ). SMAQ rose significantly and disproportionately compared to the rise in CO. SMAQ more than doubled from a mean of $448 \pm 124 \mathrm{cc}$ at baseline to a mean of $921 \pm 321 \mathrm{cc}$ at $10 \mathrm{~min}$, and remained elevated throughout drug infusion. SMAR and TPR both decreased significantly. Although percentage shunt was low at baseline, $1.79 \pm 0.94 \%$, and did not change, both $\mathrm{AVAQ}$ and $\mathrm{NCQ}$ increased significantly during drug infusion. The increase in AVAQ was transient, but NCQ remained elevated throughout infusion. PVP increased significantly, and the change in PVP correlated significantly with the change in AVAQ at $30 \mathrm{~min}$, a time when AVAQ was not elevated significantly above baseline levels. Nutrient capillary flow comprised $\geq 98 \%$ of total SMAQ during the experiment and, along with total SMAQ, doubled and remained elevated throughout drug infusion. Although glucagon may increase PVP by slightly increasing the absolute volume of mesenteric shunt flow, its primary action is that of a potent mesenteric arterial dilator, increasing NCQ strikingly more than AVAQ.
\end{abstract}

Glucagon is a polypeptide hormone that has a variety of actions other than its known hyperglycemic effect. When administered in pharmacologic doses, glucagon increases superior mesenteric artery (SMA) blood flow and lowers mesenteric vascular resistance $[7,15,19,21,26,29,30]$. These splanchnic hemodynamic effects have generally been attributed to arterial dilatation.

Recently, the supposition that glucagon causes mesenteric arteriovenous shunting has been reintroduced into the surgical literature $[20,24]$. Previous investigators have shown that portal venous pressure and portal venous oxygen concentration rise during glucagon infusion, and have suggested that this was a reflection of mesenteric shunting $[12,13]$. To our knowledge, previous studies have not directly examined whether glucagon causes arteriovenous shunting in the superior mesenteric artery circulation.

In the current investigation, the effect of glucagon on superior mesenteric artery arteriovenous anastomotic shunting was measured directly using the radioactive microsphere technique in a canine model. Quantification of the percentage of blood flow passing through superior mesenteric artery shunts allowed determination of the volume of nonshunt flow which was of a nutritive nature as it passed through the 
capillary circulation. The objective of this experiment was to precisely define the mechanisms by which pharmacologic doses of glucagon alter superior mesenteric artery blood flow.

\section{MATERIALS AND METHODS}

Six adult mongrel dogs weighing 24 to $37 \mathrm{~kg}$ were anesthetized with $30 \mathrm{mg} / \mathrm{kg}$ sodium pentobarbital with supplemental pentobarbital anesthesia $(5 \mathrm{mg} / \mathrm{kg})$ administered as needed. Experimental manipulations were not performed within 40 min of anesthetic administration. Dogs were intubated and mechanically ventilated to maintain arterial blood gases within physiologic range. Hypoxic dogs or those with abnormal acid-base status were not studied. An esophageal temperature probe was inserted for measurement of core temperature. Normothemia was carefully maintained during the experiment. Lactated Ringer's solution ( $30 \mathrm{cc} / \mathrm{kg}$ body wt) was infused as a bolus during the early operative manipulations, and $20 \mathrm{cc} / \mathrm{kg} / \mathrm{hr}$ Ringer's solution was administered over the $30 \mathrm{~min}$ when glucagon was administered and hemodynamic measurements were performed.

A 14-gauge polyethylene carotid arterial catheter, a centrally threaded 21-gauge Teflon jugular venous catheter, and a 7french thermodilution Swan-Ganz catheter with its tip in the pulmonary artery were inserted by way of the cervical vessels.

The superior mesenteric artery was carefully exposed at its origin, and a nonoccluding, precalibrated $12-$ or $13-\mathrm{mm}$-diameter electromagnetic flow probe was placed about the proximal artery. A 21gauge polyethylene catheter was inserted into one of the superior mesenteric artery arcade branches. This catheter was threaded into the superior mesenteric artery 2 to 3 $\mathrm{cm}$ from its aortic origin, such that its tip was proximal to all SMA arterial branches. An 18-gauge polyethylene catheter was threaded into the portal vein proximal to its bifurcation by way of a pancreaticoduodenal branch.
The right lobe of the liver was brought outside the chest through diaphragmatic and thoracotomy incisions. This was facilitated by a generous right lateral thoracotomy incision through the 9th or 10th intercostal space with resection of an adjacent rib. Similarly, the right hemidiaphragm was generously incised and a portion excised. There was no obstruction to hepatic arterial and portal venous inflow or hepatic venous outflow from the externalized liver segment. This maneuver did not alter portal venous pressure in any animal. The dislocated liver lobe was wrapped loosely with a moist laparotomy pack. A nuclear scanner calibrated for the detection of technetium- $99 \mathrm{~m}$ was fixed in place immediately over the liver segment. The midline incision was reapproximated to secure the remaining abdominal contents within the peritoneal cavity. The abdomen and chest were shielded from the scanner using a lead apron.

Central venous pressure, systemic arterial pressure, and portal venous pressure were continuously monitored using pressure transducers attached to a multichannel recorder. Cardiac output was measured by the thermodilution technique. Total superior mesenteric artery flow was measured using a carefully calibrated electromagnetic square wave flow probe, and was continuously recorded on the multichannel recorder.

Radioactive technetium-99m-labeled albumin microspheres with a mean diameter of $20 \mu \mathrm{m}$ were freshly prepared. These spheres varied in size from 10 to $35 \mu \mathrm{m}$ such that only $5 \%$ of the spheres were outside this range. Microspheres were discarded if significant amounts of unlabeled radioactivity or gross abnormalities in size were detected. Less than $1 \%$ of the preparations' radioactivity was not bound by microspheres, as determined by instant thinlayer chromatography.

Shunt flow through arteriovenous anastomotic channels (AVA) was determined by techniques paralleling those employed 
for the determination of shunt in the canine hindlimb [3]. A known quantity of technetium-99m-labeled microspheres was injected into the superior mesenteric artery. The change in counts per minute over the externalized liver segment after injection was monitored using a nuclear scanner calibrated for measurement of ${ }^{99 m} \mathrm{Tc}$, having a $12.7-\mathrm{cm}$ detector with a straight bore collimator. It was assumed that spheres passing through AVA in the mesenteric circulation would pass from the arterial to the portal venous circulation and be trapped in the liver. Delaney and others have shown the liver to be an adequate trap for microspheres in experiments measuring gastrointestinal arteriovenous anastomotic shunting or blood flow distribution $[5,9,10]$.

Spheres not passing through arteriovenous anastomoses would theoretically be trapped in the mesenteric capillary circulation as the mean diameter of canine mesenteric capillaries has been shown to be approximately $7.38 \mu \mathrm{m}$ [1]. A reference " $100 \%$ shunt" was established by measuring the change in radioactivity over the liver segment after injecting a known dose of radioactive microspheres into the portal vein. Data thus generated allowed for calculation of the change in counts per minute per microcurie injected or "shunted." The actual doses injected were determined by using a radioisotope dose calibrator adjusted to detect technetium- $99 \mathrm{~m}$.

Radioactivity of syringes containing the microspheres was measured in microcuries both before and after injection. The actual doses injected were determined considering the rapid radioactive decay of technetium- $99 \mathrm{~m}$. Microspheres were injected into the superior mesenteric artery against flow in a rapid fashion to insure adequate mixing [5]. Superior mesenteric artery total flow was not disturbed. The volume of microsphere injectate was $\leq 0.1$ cc and contained from 25,000 to 37,500 microspheres. Syringes containing the microspheres were flushed slowly three times with $1 \mathrm{cc}$ of blood aspirated through the polyethylene tubing. The radioactivity of the polyethylene tubing in the superior mesenteric artery and portal vein, as well as the stopcocks attached to this tubing, was minimal and was therefore not considered in any calculations.

Cardiac output $(\mathrm{CO})$, mean arterial pressure (MAP), central venous pressure (CVP), total peripheral vascular resistance (TPR $=(\mathrm{MAP}-\mathrm{CVP}) / \mathrm{CO} \times 79.9$ in dyn-sec $/$ $\mathrm{cm}^{5}$ ), and superior mesenteric arterial resistance $(\mathrm{SMAR}=(\mathrm{MAP}-\mathrm{PVP}) / \mathrm{SMAQ}$ (liters $/ \mathrm{min}) \times 79.9$ in dyn-sec/cm ${ }^{5}$ were derived in a standard fashion. The percentage of superior mesenteric blood flow passing through arteriovenous anastomoses was calculated as:

$$
\% \text { Shunt }=\frac{\frac{\Delta \text { cpm over liver after arterial injection }}{\text { actual dose of arterial injection }}}{\frac{\Delta \text { cpm over liver after portal venous injection }}{\text { actual dose of portal venous injection }}} \times 100 \text {. }
$$

The volume flow through these shunts was calculated as: Shunt flow = total SMAQ $\times \%$ shunt. The volume of nonshunted nutrient blood flow delivered to the mesenteric capillary circulation was calculated using the formula:

SMA nutrient flow (SMA-NCQ)

$$
\text { = total SMAQ - shunt flow. }
$$

Hemodynamic measurements were made after achieving a stable baseline, and at 10,20 , and $30 \mathrm{~min}$ during infusion of 1 $\mu \mathrm{g} / \mathrm{kg} / \mathrm{min}$ glucagon by way of a peripheral vein. Baseline determinations of shunt levels were performed twice in each dog. Values obtained were reproducible and did not vary significantly from one another. 
TABLE 1

Major Hemodynamic EfFects of Glucagon Infusion

\begin{tabular}{lcccc}
\hline & & \multicolumn{3}{c}{ Glucagon infusion period } \\
\cline { 3 - 5 } & Baseline & $10 \mathrm{~min}$ & $20 \mathrm{~min}$ & $30 \mathrm{~min}$ \\
\hline $\begin{array}{l}\text { Cardiac output }(\mathrm{V} / \mathrm{min}) \\
\begin{array}{c}\text { Mean arterial pressure } \\
(\mathrm{mm} \mathrm{Hg})\end{array}\end{array}$ & $4.16 \pm 0.74$ & $4.71 \pm 1.2(\mathrm{~ns})$ & $4.95 \pm 1.02^{*}$ & $4.92 \pm 0.93(\mathrm{~ns})$ \\
$\begin{array}{c}\text { Total peripheral resistance } \\
(\text { dyn-sec)/(cm }\end{array}$ & $112 \pm 13$ & $104 \pm 17^{*}$ & $94 \pm 16^{* *}$ & $94 \pm 10^{*}$ \\
\hline
\end{tabular}

Note. Data assessed for statistical significance in comparison to baseline values using two-tailed paired $t$ test. Measurements expressed as $\bar{X} \pm 1 \mathrm{SD}$.

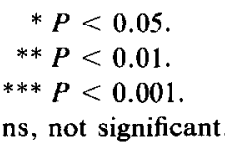

Lungs of several dogs were scanned, and minimal radioactivity was documented, confirming suitable hepatic trapping of microspheres. Pearson product-moment correlation coefficients were calculated for the various parameters making a data matrix with the MIDAS statistical computer program. When appropriate, linear regression analyses, two-tailed paired $t$ tests, and Wilcoxon signed-rank tests were performed in a standard fashion.

\section{RESULTS}

Glucagon elicited major hemodynamic alterations (Table 1). Cardiac output was increased throughout the infusion. The cardiac output increased from a baseline of $4.16 \pm 0.74$ to $4.95 \pm 1.02$ liters $/ \mathrm{min}$ at $20 \mathrm{~min}$ infusion. This change was significant $(P<0.05)$, and the increase in cardiac output approached significance at $30 \mathrm{~min}$ $(0.05<P<0.1)$. The infusion resulted in a significant and progressive decline in mean arterial pressure and total peripheral vascular resistance compared to baseline. Linear regression analysis documented that TPR decreased significantly with time through the infusion, as did MAP.

The effect on superior mesenteric artery blood flow was marked (Table 2). By 10 min, superior mesenteric artery flow virtually doubled from $448 \pm 124$ to 921 $\pm 321 \mathrm{cc} / \mathrm{min}$. Superior mesenteric artery flow remained significantly elevated for the duration of glucagon infusion. Mesenteric vascular resistance at $10 \mathrm{~min}$ had fallen to approximately half baseline levels and remained significantly lower than controls for the duration of the experiment. An inverse linear correlation between superior mesenteric artery flow and resistance was documented throughout the study $(P<0.05)$.

Superior mesenteric artery blood flow did not appear statistically related to cardiac output. Importantly, superior mesenteric artery flow comprised a progressively larger portion of cardiac output during glucagon administration. At baseline, $10.8 \%$ of the cardiac output was distributed to the superior mesenteric circulation. At 10 and $20 \mathrm{~min}$ this rose to 20.2 and $16.9 \%$, respectively $(P<0.05)$. The disproportionate rise in mesenteric blood flow, and lack of its correlation with cardiac output implies that increased mesenteric blood flow does not result solely from increased cardiac output.

The percentage of blood flow shunted through AVA in the superior mesenteric arterial circulation in baseline measurements was low, $1.79 \pm 0.94 \%$ (Table 2). 
TABLE 2

Mesenteric Microcirculatory Effects of Glucagon Infusion

\begin{tabular}{lcccc}
\hline & & \multicolumn{3}{c}{ Glucagon infusion period } \\
\cline { 3 - 5 } & Baseline & $10 \mathrm{~min}$ & $20 \mathrm{~min}$ & $30 \mathrm{~min}$ \\
\hline $\begin{array}{l}\text { Superior mesenteric artery flow } \\
\text { (ml/min) }\end{array}$ & $448 \pm 124$ & $921 \pm 321^{* *}$ & $828 \pm 260^{* *}$ & $755 \pm 225^{* *}$ \\
$\begin{array}{l}\text { Portal venous pressure (mm Hg) } \\
\text { Superior mesenteric artery } \\
\text { resistance (dyn-sec)/cm }\end{array}$ & $1.0 \pm 1.0$ & $2.8 \pm 1.2^{* *}$ & $3.5 \pm 1.7^{* *}$ & $3.5 \pm 1.8^{*}$ \\
$\begin{array}{l}\text { Percentage superior mesenteric } \\
\text { artery blood flow shunted } \\
\text { through AVA }\end{array}$ & $20,738 \pm 3,610$ & $9361 \pm 1860^{* * *}$ & $9194 \pm 1660^{* * *}$ & $10,053 \pm 2,620^{* * *}$ \\
$\begin{array}{l}\text { Superior mescnteric artery } \\
\text { AVA flow (ml/min) }\end{array}$ & $1.79 \pm 0.94$ & $1.61 \pm 0.82(\mathrm{~ns})$ & $1.53 \pm 0.83(\mathrm{~ns})$ & $1.39 \pm 0.75(\mathrm{~ns})$ \\
$\begin{array}{l}\text { Superior mesenteric artery } \\
\text { nutrient capillary flow }\end{array}$ & $7.35 \pm 3.6$ & $13.1 \pm 6.1^{*}$ & $11.5 \pm 6.3^{*}$ & $9.8 \pm 5.9(\mathrm{~ns})$ \\
$\quad$ (ml/min) & $441 \pm 125$ & $908 \pm 322^{*}$ & $818 \pm 262^{*}$ & $745 \pm 227^{*}$ \\
\hline
\end{tabular}

Note. Data assessed for statistical significance in comparison to baseline values using Wilcoxon signed-rank tests and two-tailed paired $t$ test. Measurements expressed as $\bar{X} \pm 1$ SD.

$* P<0.05$.

** $P<0.01$.

$* * * P<0.001$.

ns, not significant.

This value was similar to those previously reported using different techniques $[5,6$, $9,11]$. The percentage of SMAQ passing through AVA following glucagon infusion did not change significantly from baseline, although it tended to decrease. The absolute volume of shunt flow passing through AVAs significantly increased from baseline at 10 and $20 \mathrm{~min}$ of glucagon infusion. The volume of this shunt flow was very small in comparison to the increase in mesenteric nutrient flow. The superior mesenteric arterial nonshunt nutrient flow rose markedly and significantly during drug infusion, and comprised greater than $98 \%$ of total mesenteric flow. Nutrient capillary flow correlated inversely with SMAR throughout the experiment $(P<0.05)$.

Portal venous pressure (PVP) rose significantly during glucagon infusion. Though assumed to be a reflection of the markedly increased SMAQ, the increase in PVP did not correlate with the rise in SMAQ or NCQ. Despite the relatively small volume of shunt flow, the increase in PVP during glucagon infusion correlated with the change in shunt flow at $30 \mathrm{~min}$, at a time when AVAQ was not elevated above control values. PVP did increase significantly with time throughout the experiment.

\section{DISCUSSION}

The presence and functional significance of arteriovenous anastomoses in the superior mesenteric artery circulation remain controversial $[1,5,6,9,11]$. Investigators have reported variable results in determining the percentage mesenteric shunt, from a negligible value to $41-51 \%$ shunt $[11,17]$. The former study used $44-\mu \mathrm{m}$ spheres, and the latter used $8-\mu \mathrm{m}$ spheres. Since the mean diameter of canine mesenteric capillaries is approximately 7.38 $\mu \mathrm{m}$, results of experiments utilizing spheres small enough to traverse the capillary channels must be interpreted with caution $[1,17]$. Earlier studies using appropriately sized microspheres have indicated that 
shunting in the canine superior mesenteric artery circulation accounts for approximately 1 to $4 \%$ of this vessel's normal blood flow $[5,6,11]$. Although employing different techniques for estimation of shunt, these experiments yielded similar results. Delaney found $0.97 \%$ mean shunt in the mesenteric circulation using a needle injection into the superior mesenteric artery of anesthetized dogs, and a $2.89 \%$ baseline shunt using an indwelling mesenteric catheter in the awake animal [5]. This investigator reported that spheres $20 \mu \mathrm{m}$ in size were adequately trapped in the liver with only $0.02 \%$ of their radioactivity lodged in the lungs following portal venous injection [5]. Similar results have been reported by other investigators [9]. Greenway and Oshiro reported that less than $0.3 \%$ of radioactivity injected into canine celiac artery and portal vein was found in the lung [10].

Glucagon in pharmacologic doses has been reported to increase celiac, superior mesenteric artery, pancreatic, and liver blood flow $[2,4,7,14,15,16,19,21,25,27,28,29,30]$. The increase in hepatic blood flow is thought due to an increase in both portal venous flow and hepatic artery flow [14]. Glucagon significantly decreases vascular resistance in the hepatic, celiac, and superior mesenteric artery circulations, as well as significantly reducing total peripheral vascular resistance [19]. Glucagon has been shown to be a positive inotrope as well as positive chronotrope $[8,22]$, and thus increases cardiac output. In the present experiment glucagon increased superior mesenteric artery blood flow out of proportion to the rise in cardiac output. This is consistent with previous reports in the literature, and indicates that glucagon acts as a selective mesenteric arterial dilator [19].

Glucagon has been reported to increase portal venous pressure, increase portal venous oxygen concentration, and decrease splanchnic arteriovenous oxygen differences [12, 13]. Based on these findings, speculation arose that glucagon caused mesenteric arteriovenous anastomotic shunting $[12,13,20,24]$. Other experiments using indirect methods examining oxygen consumption have not supported this contention [23]. To our knowledge, the effect of glucagon on mesenteric arteriovenous shunting has not been previously measured directly. In the present study the fact that changes in portal venous pressure correlated significantly with the changes in superior mesenteric artery shunt flow only at 30 min does not refute the assumption that glucagon increases mesenteric arteriovenous anastomotic shunting. However, the increased volume of shunt flow induced by glucagon was miniscule compared to the increase in total nonshunted nutrient superior mesenteric artery blood flow. Significant increases in portal venous pressure at 10 and $20 \mathrm{~min}$ during infusion did not correlate with shunt flow, which had already begun to decrease and was at its lowest mean value during glucagon infusion at 30 min. It is difficult to believe that the increase in portal venous pressure was due solely to the small volume of increased shunt flow.

This present study did not examine the distribution of blood flow within the gut wall. Glucagon has been shown to increase whole gut and villous tip blood flow in normal dogs [1]. In addition, glucagon has been shown to increase blood flow to all layers of the gut during digoxin-induced vasoconstriction in the dog [27]. Increased superior mesenteric artery blood flow in the presence of both a significant SMA stenosis and concomitant digoxin-induced vasoconstriction has also been demonstrated experimentally [18]. In the present study glucagon did not increase the percentage shunt but transiently increased absolute shunt flow. These former results can be explained by drug-induced superior mesenteric arteriolar dilatation with a passive increase in blood flow through AVAs and capillaries, both of which are presumably distal to the arterioles. These splanchnic hemodynamic effects of glucagon and the ability to achieve these effects by intravenous, as opposed to selective intraarterial administration, make the drug a theoretically 
attractive choice as an adjunct in the management of intestinal ischemia.

\section{REFERENCES}

1. Bond, J. H., and Levitt, M. D. Use of microspheres to measure small intestinal villus blood Hlow in the dog. Amer. J. Physiol. 236: E577, 1979.

2. Bower, M. G., Okude, S., Jolley, J. B., and Smith, L. J. Hemodynamic effects of glucagon. Following hemorrhagic and endotoxic shock in the dog. Arch. Surg. 101: 411, 1970.

3. Cronenwett, J. L., and Lindenauer, S. M. Direct measurement of arteriovenous anastomotic blood flow after lumbar sympathectomy. Surgery 82: 82, 1977.

4. Darle, N., Lim, R. C., Jr., and Blaisdell, F. W. Effect of glucagon on total liver blood flow in hemorrhagic shock. Acta Chir. Scand. 140: 217, 1974.

5. Delaney, J. P. Arteriovenous anastomotic blood flow in the mesenteric organs. Amer. J. Physiol. 216: 1556, 1969.

6. Fan, F. C., Schuessler, G. B., Chen, R. Y. Z., and Chien, S. Determinations of blood flow and shunting of 9- and $15-\mu \mathrm{m}$ spheres in regional beds. Amer. J. Physiol. 251: H25, 1979.

7. Fasth, S., and Julten, L. The effect of glucagon on intestinal motility and blood flow. Acta Physiol. Scand. 83: 169, 1971.

8. Glick, G., Parmley, W. W., Wechsler, A. S., and Sonnenblick, E. H. Glucagon: Its enhancement of cardiac performance in the cat and dog and persistance of its inotropic action despite beta-receptor blockade with propranolol. Circ. Res. 22: 789, 1968.

9. Greenway, C. V., and Murthy, V. S. Effects of vasopressin and isoprenaline infusions on the distribution of blood flow in the intestine: criteria for the validity of microsphere studies. Brit. $J$. Pharmacol. 26: 177, 1972.

10. Greenway, C. V., and Oshiro. Comparison of the effects of hepatic nerve stimulation on arterial flow, distribution of arterial and portal flows and blood content in the livers of anesthetized cats and dogs. J. Physiol. (Lond.) 227: 487, 1972.

11. Grim, E., and Lindseth, E. O. Distribution of blood flow to the tissues of the small intestine of the dog. Univ. Minn. Med. Bull. 30: 138, 1958.

12. Jensen, H. E. The effect of glucagon on pressure and oxygen saturation of splanchnic venous blood. Amer. J. Dig. Dis. 11: 447, 1966.

13. Jensen, H. E., and Necheles, H. Hemodynamic effects of glucagon in the splanchnic area. Ill. Med. J. 130: 49, 1966.

14. Kock, N. G., Roding, B., Hahnloser, P., Tibblin, S., and Schenk, W. G., Jr. The effect of glucagon on hepatic blood flow. An experimental study in the dog. Arch. Surg. 100: 147, 1970.
15. Kock, N. G., Tibblin, S., and Schenk, W. G., Jr. Hemodynamic responses to glucagon: An experimental study of central, visceral and peripheral effects. Ann. Surg. 171: 373, 1970.

16. Lanciault, G., Fang, W. F., Jacobson, E. D., and Bowen, J. C. Evaluation of potential agents for treatment of nonocclusive mesenteric ischemia in the dog. Circ. Shock 3: 239, 1976.

17. Leonard, J. L., Emery, R. W., Einzig, S., Nicoloff, D. M., and Fox, I. J. Evidence for arteriovenous communications in the gastrointestinal tract. Surg. Forum 28: 419, 1977.

18. Levinsky, R. A., Lewis, R. M., Bynum, T. E., and Hanley, H. G. Digoxin induced intestinal vasoconstriction. The effects of proximal arterial stenosis and glucagon administration. Circulation 52: $130,1975$.

19. Madden, J. J., Jr., Ludewig, R. M., and Wangensteen, S. L. Effects of glucagon on the splanchnic and the systemic circulation. Amer. J. Surg. 122: 85, 1971 .

20. Modlin, I. M., and Jaffe, B. M. Clinical significance of glucagon. Surgery 87: 470, 1980.

21. Ohnhaus, E. E. The effect of glucagon on the distribution of blood flow in the splanchnic area. Life Sci. 11: 1155, 1972.

22. Parmley, W. W., and Sonnenblick, E. H. Glucagon: A new agent in cardiac therapy. Amer. J. Cardiol. 27: 298, 1971.

23. Pissotis, C., Vasilopoulos, P., Kapellakis, G., and Androulakis, G. Effect of glucagon infusion on splanchnic blood flow and $\mathrm{O}_{2}$ consumption in normal and hypovolemic conditions. Eur. J. Surg. Res. 10: 48, 1978.

24. Proctor, J. H., Wood, J. J., and Palladino, W. G. The effect of glucagon on hepatic cellular energetics during a low flow state. Surgery 87: 369 , 1980.

25. Ross, G. Regional circulatory effects of pancreatic glucagon. Brit. J. Pharmacol. 38: 735, 1970.

26. Schumer, W., Miller, B., Nichols, R. L., McDonald, G. O., Nyhus, L. M. Metabolic and microcirculatory effects of glucagon in hypovolemic shock. Arch. Surg. 107: 176, 1973.

27. Schwaiger, M., Fondacardo, J. D., and Jacobson, E. D. Effects of glucagon histamine, and perhexiline on the ischemic canine mesenteric circulation. Gastroenterology 27: 730, 1979.

28. Tibblin, S., Kock, N. G., and Schenk, W. G., Jr. Dissociation of the hyperglycemic and vascular effects of glucagon. Surgery 67: 816, 1970.

29. Tibblin, S., Kock, N. G., and Schenk, W. G., Jr. Splanchnic hemodynamic responses to glucagon. Arch. Surg. 100: 84, 1970.

30. Ulano, H. B., Treat, E., Shanbour, L. L., and Jacobson, E. D. Selective dilation of the constricted superior mesenteric artery. Gastroenterology 62: 39, 1972. 